\title{
Debunking the myth of the hard-to-reach farmer: Effective communication on udder health
}

\author{
J. Jansen, ${ }^{\star 1}$ C. D. M. Steuten, ${ }^{*}$ R. J. Renes, ${ }^{*}$ N. Aarts,${ }^{*} \dagger$ and T. J. G. M. Lam \\ ${ }^{*}$ Communication Science, Wageningen University, Wageningen, the Netherlands \\ †Communication Science, University of Amsterdam, Amsterdam, the Netherlands \\ ‡Dutch Udder Health Centre UGCN at GD Animal Health Service Ltd., Deventer, the Netherlands
}

\section{ABSTRACT}

Worldwide, programs to control mastitis are implemented using different strategies to reach farmers. Even though education materials and best practices may be technically optimal, they need to be used to be successful. Thus, effective communication with farmers is essential in order to change their behavior and to improve their farm management. During a Dutch national mastitis control program, a substantial number of farmers seemed to be hard to reach with information on udder health. Consequently, this study was designed to provide insight into the attitude and motivation of such farmers. In the period of October 2007 to July 2008, 24 in-depth, semistructured interviews were conducted with farmers whose veterinarians considered to be difficult to approach with advice on udder health management (8 practices, 3 farmers from each practice). The interviews included questions about the farms and the farmers, their attitude and behavior regarding mastitis, and their information sources and social environment. The results show that so-called hard-to-reach farmers were not always badly informed about udder health and did not always experience problems with mastitis. These ostensibly unreachable farmers were not a homogeneous group, but rather could be divided into 4 categories based on their trust in external information sources regarding mastitis and their orientation toward the outside world: proactivists, do-it-yourselfers, waitand-see-ers, and reclusive traditionalists. There are ample opportunities to reach hard-to-reach farmers, provided that the communication strategies are tailored to their specific needs. There is especially much to gain in communication with do-it-yourselfers and wait-and-see-ers, but this demands a more proactive role on the part of veterinarians and extension specialists. Different types of farmers need to be approached in different ways and through different channels with

Received October 5, 2009.

Accepted November 11, 2009.

${ }^{1}$ Corresponding author: jolanda.jansen@wur.nl information on udder health. Consequently, this study can contribute to the optimization of future programs designed to control and prevent diseases.

Key words: mastitis, communication, education, extension

\section{INTRODUCTION}

Mastitis is one of the main health issues in dairy production (Bradley, 2002; LeBlanc et al., 2006). As a result, mastitis control programs are implemented in various countries using different strategies to reach farmers. Most of these control programs focus on the development of education materials and recommendations for best practices. Although this information may be technically optimal for decreasing mastitis, to be implemented it has to be effectively and consistently communicated to farmers (Chase et al., 2006; LeBlanc et al., 2006). Mastitis control programs worldwide find that, despite all efforts, not all farmers are reached by mastitis information. A study of a national mastitis control program in the Netherlands showed that a substantial group of farmers did not participate in the organized udder health study groups and were not familiar with the developed education materials (Lam et al., 2007; Jansen et al., 2010). Veterinarians seem to have similar experiences and mention that it can be difficult to reach farmers who apparently have no demand for information (Mee, 2007). There always seems to be a group of farmers that is hard to reach with mastitis information. It may be assumed that these so-called hard-to-reach farmers are not well informed about mastitis prevention and, because of this lack of information, could have more udder health problems than average. However, little research has been done on this subject and not much is known about this group of hard-toreach-farmers and their motivation, attitude, and information sources in the context of mastitis prevention. In general, it can be expected that the personalities, attitudes, motivations, and objectives of the farmers influence their farm management and udder health (Barkema et al., 1999; Leeuwis, 2004) and that these is- 
sues do not follow simple, rational cause-effect patterns (Andersen and Enevoldsen, 2004). On the whole, farmers' perspectives are rarely studied, probably because they are complex, context-related, and contain many nonquantifiable elements (Vaarst et al., 2002). Consequently, qualitative methods rather than quantitative surveys should be used to include farmers' perspectives in evaluations of agricultural extension (Andersen and Enevoldsen, 2004; Burton, 2004).

Using qualitative, semistructured interviews, this exploratory study aimed to provide insight into the attitudes, motivations, and information-seeking behaviors of farmers who were presumed by their veterinarians to be unreachable in relation to udder health information. Having a better understanding of this group will contribute to the optimization of future programs designed to control and prevent mastitis and other animal diseases.

\section{MATERIALS AND METHODS}

\section{The Dutch National Mastitis Control Program}

In 2005 , a project was initiated to improve udder health in the Netherlands: the 5 -yr mastitis control program of the Dutch Udder Health Centre (UGCN). This project consists of knowledge transfer to farmers, veterinarians, and extension specialists and of fundamental and applied research on mastitis. The project includes various communication strategies designed to reach as many farmers as possible and to change farmers' behavior regarding mastitis management (Lam et al., 2007; Jansen et al., 2010). The communication strategies used in the udder health project consist of 2 main routes: a direct approach via articles in farm magazines, presentations at agricultural fairs, and mailings to all dairy farms, and an indirect approach via veterinarians as intermediaries between UGCN and the farmer. Particular attention is paid to the indirect route because interpersonal communication by trusted information sources is proven to be very effective (Leeuwis, 2004). In addition, the farmer considers the veterinarian to be an important and highly respected information source with regard to udder health, and the veterinarian has easy access to the farmer and can talk about udder health when they visit the farm (Kuiper et al., 2005; Jansen et al., 2008). Therefore, the veterinarian was chosen as the preferred interpersonal connection between UGCN and the farmer, and veterinarians play an important role in the udder health project.

During the project, thematic study group education materials were developed for veterinarians who were supported to set up on-farm study group meetings. In 2008 , almost 200 veterinary practices participated in the program. Through these veterinary practices, more than 17,000 dairy farmers (approximately $78 \%$ of all Dutch dairy farmers) had direct access to the udder health project. Of this group, 3,169 farmers (approximately $14 \%$ of all Dutch dairy farmers) participated in the on-farm study groups that were organized by their veterinarians.

\section{Selection of Dairy Farmers}

To select dairy farmers that were hard to reach with udder health information, 8 veterinary practices that participated in the udder health program were visited and asked to mention at least 4 dairy farmers in their practice that they perceived to be hard to reach within the project and with udder health information in general. They were asked to describe their relationship with that specific farmer and the udder health situation of these farms. Of the reported farmers, 37 were randomly contacted until 24 (3 per practice) were willing to participate in this study. Thirteen farmers did not want to participate because they were either too busy or not interested.

\section{Qualitative Interviews}

A qualitative interview is a methodology that can be used to get a better understanding of individual farmers' mindsets (e.g., their opinions, values, attitudes, and motivations) rather than quantifying these factors among a representative group of people (Strauss and Corbin, 1990). It is an explorative method that can be used to understand the relationships between different arguments used by farmers in conversations about mastitis (Wester and Peters, 2004). The conducted interviews were semistructured, meaning that farmers were initially asked general questions, such as "To what extent is mastitis a problem for you?" Depending on the farmer's answers, more specific questions were then asked in order to explore the farmer's opinion about the topic raised (Vaarst et al., 2002; Hektoen, 2004; Vaarst and Sørensen, 2009). During the interview, the following topics where discussed: 1) description of farm and farmer; 2) farmer's risk perception; 3) prevention and treatment of mastitis; 4) farmer's need for information; 5) use of mastitis information sources; 6) farmer's interaction with veterinarian; and 7) farmer's familiarity with, and opinion about, the udder health project. A full description of the interview structure can be found in Appendix Table A1. All farmers were visited between November 2007 and June 2008 and were interviewed by the same person (second author). The interviewed farmers were responsible for the herd management on the farms. The length of the interviews ranged from 26 to $78 \mathrm{~min}$, and all interviews were digitally recorded. 


\section{Data Analyses}

All interviews were transcribed in full. Grounded theory analysis was used to analyze the data (Strauss and Corbin, 1990), following the 4-step methodology of Wester and Peters (2004). First, the data were explored to get an overview of all farmers' answers to the questions asked. Second, the data were specified using main themes or sensitizing concepts that frequently cropped up in farmers' answers. Third, the data were reduced by categorizing the farmers within these concepts. Fourth and finally, the sensitizing concepts were compared with each other and were integrated to formulate a theory based upon the transcribed interviews.

\section{RESULTS}

\section{Descriptive Results}

The average farmer interviewed was $42 \mathrm{yr}$ of age (range: 27-62) and milked 88 dairy cows (range: 52145 ) on 54 ha of land (range: $35-95$ ). The average milk production quota was $714,000 \mathrm{~kg}$ of milk/yr, ranging from 400,000 to $1,130,000 \mathrm{~kg} / \mathrm{yr}$. The most commonly used milking parlor was a fishbone milking parlor (n $=18)$, followed by a side-by-side parlor $(\mathrm{n}=4)$. One farm used an automatic milking system. All but 1 farm participated in a test-day milk recording scheme. All farms were family farms managed by 1 farmer and had, on average, 1 full-time employee, usually a family member. The farmers had attended secondary agricultural school $(\mathrm{n}=3)$ or had vocational agricultural education $(\mathrm{n}=14)$ or higher agricultural education $(\mathrm{n}=7)$. The aforementioned parameters do not deviate from Dutch national averages.

In 16 cases, the udder health status for the herds of the interviewed farmers was either unknown $(\mathrm{n}=9)$ or considered to be unsatisfactory $(\mathrm{n}=7)$ by their veterinarian. Eight farms were graded by their veterinarians on a scale from 1 (worst) to 10 (best), resulting in an average score of 5.8. Some of the farmers themselves considered their herds' udder health status to be unsatisfactory $(\mathrm{n}=2)$, sufficient $(\mathrm{n}=2)$, or difficult to describe $(n=1)$, but most farmers $(n=19)$ graded themselves; this resulted in an average score of 7.1. Many farmers perceived more mastitis problems than in the past $(\mathrm{n}=10)$, some perceived similar problems $(\mathrm{n}=8)$, and some perceived fewer problems $(\mathrm{n}=6)$. All farmers stated that they would change their farm management if they either approached the bulk milk SCC penalty level $(400,000$ cells $/ \mathrm{mL})$ or encountered many clinical mastitis cases.

The farmers varied in their opinions about the treatment of mastitis. Some stated that it was easy $(n=9)$; others thought it depended on the case $(\mathrm{n}=9)$ or con- sidered it to be difficult $(\mathrm{n}=6)$. Most farmers stated that they did many things to prevent mastitis, such as postmilking teat disinfection and dry-off therapy with antibiotics. They mentioned various causes for mastitis on their farms, such as overcrowded cowsheds, nonoptimal milking machines, breeding strategy, and weather conditions. The farmers stated that the most effective way to decrease mastitis was to cull problem cows but that, for economic, sustainability, or emotional reasons, this was not always done. They also bemoaned the lack of farm-specific effective solutions other than that of culling problem cows. When, however, such preventive measures were suggested by the interviewer, they were disputed by the farmers because the farmers considered them not useful (e.g., milking gloves), too expensive (e.g., bacteriological culturing of milk, dry-off therapy, cleaning udders with 1 paper towel per cow, better feeding), or too much work (e.g., prestripping cows, milking cows with high cell counts separately), or they thought that the measures were not suitable for their current housing system (e.g., decrease overcrowding, renovate milking parlor). When asked whether they ought to pay more attention to mastitis prevention, 5 of the 24 farmers said yes.

Farmers stated that farm magazines were their most important information source for general information about udder health, whereas the veterinarian was the primary source in the case of specific questions. All farmers had contact with their veterinarian during the compulsory health monitoring visits 4 times per year and during emergency call-outs. Four farmers participated in regular monthly herd health visits, and 12 of the interviewed farmers participated in PiR-DAP, a Dutch program for farmers to share milk inspection reports online with their veterinarians. Farmers considered the relationship with their veterinarian to be $\operatorname{good}(\mathrm{n}=17)$ or mediocre $(\mathrm{n}=7)$. None of the farmers expressed the need for more advice from the veterinarian.

To exchange information on udder health with colleagues, the farmers participated in study groups (n $=12$ ) or talked about mastitis issues with colleagues individually $(\mathrm{n}=4)$. They did not know the udder health situation on other farms. Some farmers had a specific need for more mastitis information $(\mathrm{n}=2)$; others stated that the available information on udder health was not useful because it was too much of the same and no effective solutions were provided $(\mathrm{n}=3)$. Farmers sometimes disputed the received information $(\mathrm{n}=15)$ either because it could not be applied on their own farm or because they did not believe that the proposed measures would help to decrease mastitis. Some farmers $(n=9)$ felt that they received contradictory information on how to deal with problems from, for 
example, the veterinarian, the local feed advisor, or the milk equipment advisor.

If farmers could spend money on a national udder health project, they would invest in subsidized personal and expert-based support for problem farms $(\mathrm{n}=9)$ or research for more effective measures to control and prevent mastitis (e.g., to increase the general resistance of the cow by feeding and breeding policies; $\mathrm{n}=9$ ), or they would not invest and rather would depend on free market processes to decrease the number of problem farms $(\mathrm{n}=4)$.

\section{Results of In-Depth Analysis of the Interviews}

After exploration of the interview transcripts, 2 main sensitizing concepts were derived by specification of all farmers' answers in the interviews: farmers' orientation toward the external world and their trust in external relationships. After reduction of the data, farmers were categorized using these concepts.

The first concept encompasses farmers' orientation toward the external world. From the interviews, it appeared that some farmers were very open toward other farmers and information sources (e.g., "I have a lot of contact with colleagues throughout the whole country, even internationally; I get a lot of information from them."). Other farmers were very closed and focused mainly on the situation on their own farm (e.g., "Colleagues? I never look at what colleagues are doing; I don't care. They have to think for themselves and so do I.").

Farmers were categorized under this heading based on the answers they gave about 1) participation in study groups; 2) participation in regular herd health visits by the veterinarian; 3) participation in the sharing of milk inspection reports online with their veterinarian; 4) visiting open farm days; 5 ) interacting with colleagues about mastitis, including being active on boards and committees; and 6) using different information sources, such as farm magazines and the Internet (Table 1). Farmers were scored on these issues as + (positive perception or participation in these activities), 0 (neutral perception), or - (negative perception or no participation in these activities).

With regard to the second sensitizing concept, farmers' trust in external relationships, it appeared that

Table 1. Division of hard-to-reach farmers into 2 sensitizing concepts ${ }^{1}$ based on the results of qualitative, semistructured, in-depth interviews

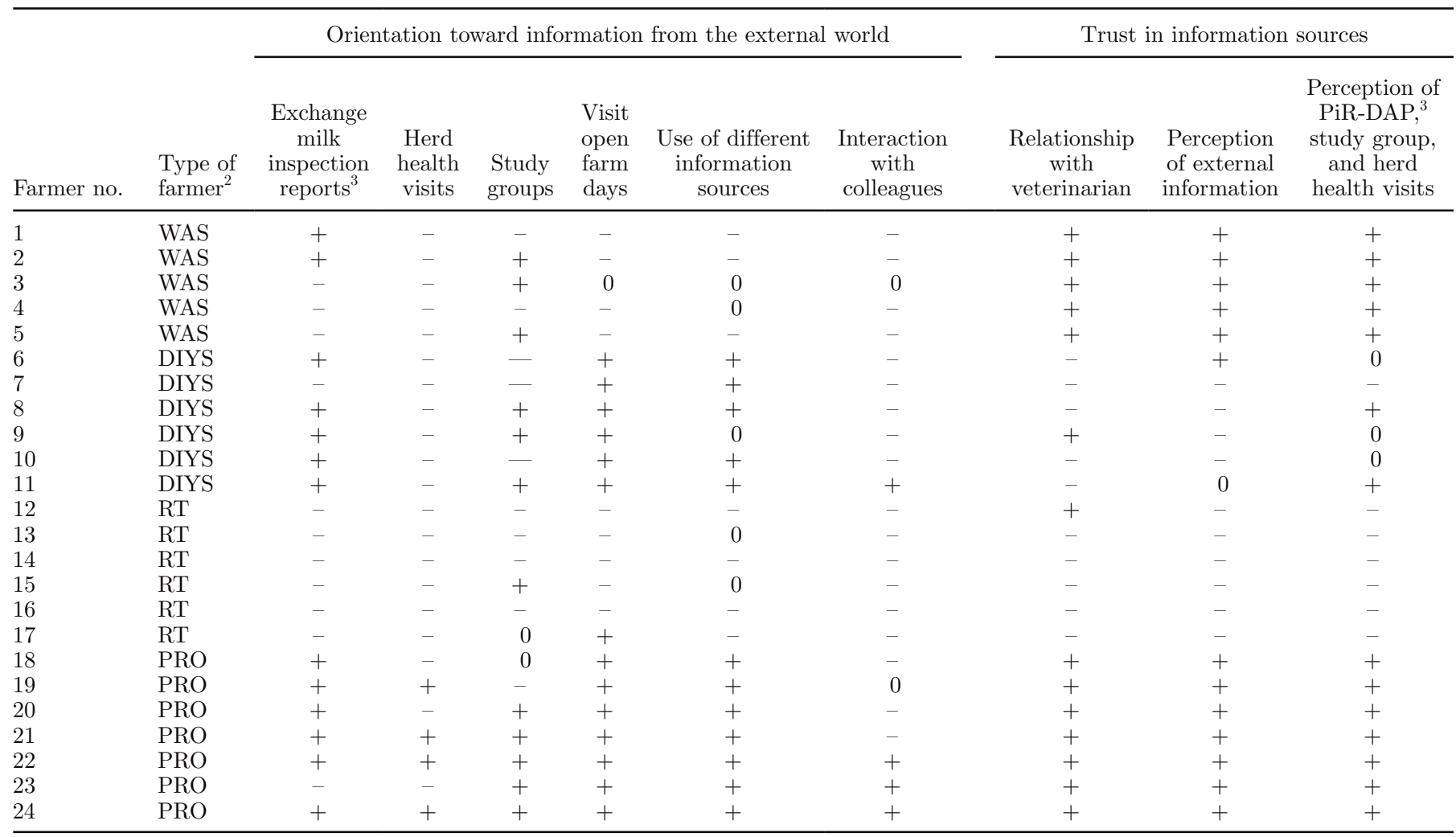

${ }^{1}$ Scores are interpretations of farmers' perceptions: $+=$ a positive perception or participation; $0=$ a neutral perception; $-=$ a negative perception or participation.

${ }^{2} \mathrm{WAS}=$ wait-and-see-er; DIYS $=$ do-it-yourselfer; $\mathrm{RT}=$ reclusive traditionalist; $\mathrm{PRO}=$ proactivist.

${ }^{3} \mathrm{~A}$ commercial online system (called PiR-DAP in the Netherlands) that is used to send milk inspection reports to the local veterinarian. 


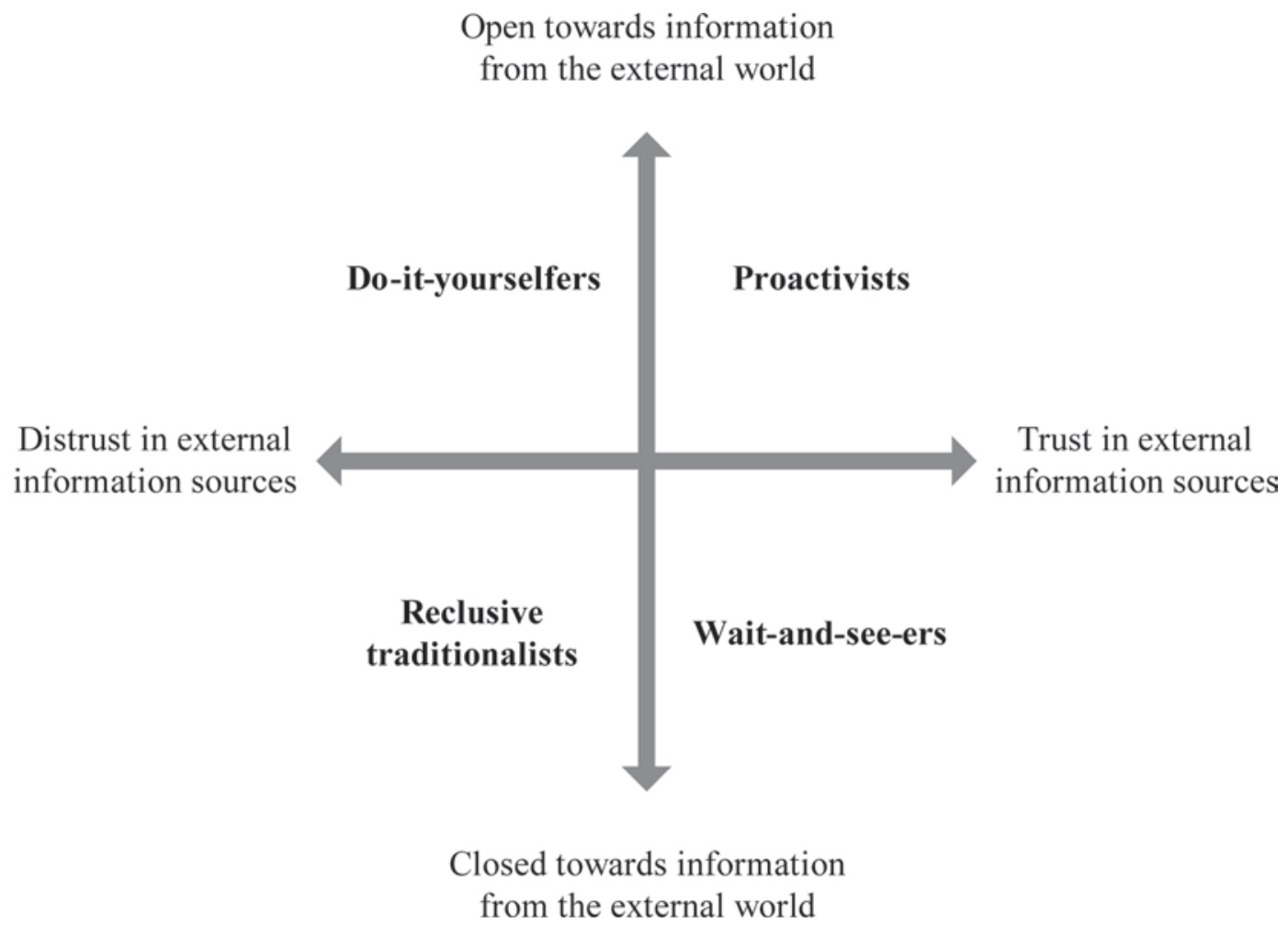

Figure 1. Different types of hard-to-reach farmers based on 24 qualitative, semistructured interviews.

some farmers had trust in information sources and the information they received (e.g., "My veterinarian takes his time, we talk about many things, and I can ask him everything; he gives advice and that goes well."). Several other farmers distrusted the information sources and the information they received (e.g., "Most of the times those vets like to treat immediately, too soon in my opinion; it costs you lots of money and only the vet benefits from it behind your back."), and other farmers had a more general distrust of organizations (e.g., "If [dairy organizations] come with new ideas, there has to be a snag somewhere. They don't do it for the farmer, no, they don't.").

Farmers were categorized under the second heading based on the answers they gave about 1) their relationship with their veterinarian; 2) their perception of external information; and 3) their perception of activities such as study groups, regular herd health monitoring visits by veterinarians, and exchange of information with others (Table 1). Farmers were scored on these issues as + (positive perception), 0 (neutral perception), or - (negative perception).

Integration of the categorizations under the 2 headings resulted in 4 different groups of farmers: proactivists, do-it-yourselfers, wait-and-see-ers, and reclusive traditionalists (Figure 1). Comparison of the different groups of farmers revealed no differences in demographic factors such as education level, age, farm size, and so on. The groups did, however, vary in udder health characteristics (Table 2).

Proactivists. A prototypical proactivist can be illustrated by the following quote: "Obviously, it is important that people from outside look at your farm; otherwise, they cannot think along with you." Of the 24 farmers interviewed, 7 were categorized as proactivists. Proactivists were outward oriented, well informed, and interested in all kinds of new developments. They were almost all members of a study group, and some even participated in multiple study groups. Colleagues and peers were important information sources, and they discussed udder health openly. Most farmers in this group rated the Internet as an important information source, and they did not mind sharing milk inspection reports with their veterinarian online. They all stated that they had a positive relationship with their veterinarian, but did not see their veterinarian as the only and most important information source because they used many different sources. All but 1 farmer in this group stated that they disagreed with the available information sometimes. Reasons for these farmers not participating in udder health project study groups included not encountering mastitis problems, being too busy, or having 
Table 2. Four types of hard-to-reach farmers and their self-reported udder health status, derived from qualitative, semistructured interviews

\begin{tabular}{|c|c|c|c|c|c|c|c|c|}
\hline $\begin{array}{l}\text { Farmer } \\
\text { no. }\end{array}$ & $\begin{array}{l}\text { Type of } \\
\text { farmer }^{1}\end{array}$ & $\begin{array}{l}\text { Mastitis is } \\
\text { most important } \\
\text { problem }\end{array}$ & $\begin{array}{l}\text { Self-reported } \\
\text { clinical mastitis } \\
\quad \text { incidence }\end{array}$ & $\begin{array}{l}\text { Average self- } \\
\text { reported BMSCC } \\
(\text { cells } / \mathrm{mL})\end{array}$ & $\begin{array}{c}\text { Farmer is } \\
\text { satisfied with } \\
\text { BMSCC level }\end{array}$ & $\begin{array}{c}\text { Satisfaction } \\
\text { level of } \\
\text { BMSCC }\end{array}$ & $\begin{array}{l}\text { Farmer's self- } \\
\text { reported grade } \\
\text { for udder health }\end{array}$ & $\begin{array}{l}\text { Veterinarian- } \\
\text { reported grade } \\
\text { for udder health }\end{array}$ \\
\hline 1 & WAS & 2 & 19 & 250,000 & no & 150,000 & satisfactory & 5 \\
\hline 3 & WAS & 1 & 52 & 325,000 & no & 200,000 & 6 & unknown \\
\hline 4 & WAS & 1 & 60 & 225,000 & no & 125,000 & 7 & unknown \\
\hline 5 & WAS & 2 & unknown & 250,000 & no & 150,000 & 6 & 4 \\
\hline 9 & DIYS & 2 & 45 & 200,000 & no & 100,000 & 7 & 5.5 \\
\hline 10 & DIYS & 0 & 55 & 240,000 & yes & - & satisfactory & unknown \\
\hline 11 & DIYS & 1 & 40 & 300,000 & no & 200,000 & 5 & unsatisfactory \\
\hline 12 & $\mathrm{RT}$ & 0 & 7 & 160,000 & yes & - & 8 & 5 \\
\hline 13 & $\mathrm{RT}$ & 0 & 13 & 160,000 & yes & - & 8 & unknown \\
\hline 14 & $\mathrm{RT}$ & 1 & 19 & 128,000 & yes & - & 8 & 4.5 \\
\hline 20 & $\mathrm{PRO}$ & 0 & 8 & 210,000 & no & 150,000 & 7.5 & 7 \\
\hline 21 & PRO & 0 & 9 & 150,000 & yes & - & 8 & 8 \\
\hline 22 & PRO & 0 & 12 & 175,000 & yes & 150,000 & 7 & 6.5 \\
\hline 23 & $\mathrm{PRO}$ & 0 & 25 & 200,000 & yes & - & 9 & unknown \\
\hline 24 & PRO & 2 & 27 & 275,000 & no & 125,000 & 6 & unsatisfactory \\
\hline
\end{tabular}

${ }^{1} \mathrm{WAS}=$ wait-and-see-er; DIYS $=$ do-it-yourselfer; $\mathrm{RT}=$ reclusive traditionalist; PRO = proactivist.

${ }^{2} 0=$ no, mastitis is not the most important problem on the farm; $1=$ yes, mastitis is an important problem on the farm, but there are other problems as well; $2=$ yes, mastitis is the most important problem on the farm.

${ }^{3}$ Clinical mastitis incidence calculated as number of cases reported by the farmer per 100 cows per year.

${ }^{4} \mathrm{BMSCC}=$ bulk milk SCC.

${ }^{5}$ Perceived udder health status on the farm, scored from 1 (very bad) to 10 (very good). Not all respondents could give an exact grade. They mentioned that in their perception the udder health situation was unsatisfactory, satisfactory, or unknown to them.

the feeling that they already knew enough and did not acquire any new information from such groups. Only 3 farmers in this group perceived mastitis as one of the main health problems on their farm (Table 2).

Do-It-Yourselfers. A prototypical do-it-yourselfer can be illustrated by the following quote: "The cost price of milk, that's what it's all about, and I don't see that the veterinarian can bring the cost price down." Of the 24 farmers interviewed, 6 were categorized as do-it-yourselfers. These farmers were active and well informed but had a critical attitude toward external information. They often disagreed with the available information and all but 1 perceived that they got a lot of contradictory information. They relied more on their own knowledge and experiences than on information from others. Although some of them were members of a study group, they did not talk much about their own mastitis situation with colleagues. Their most important information sources were farm magazines, and some also used the Internet. Their relationship with their veterinarian was very pragmatic and businesslike. Although many farmers in this group participated in online sharing of milk inspection reports with their veterinarian, they perceived the costs of the standard herd health visits as an important argument for having as little contact as possible with the veterinarian. When problems occurred, they did not hesitate to contact the veterinarian or another advisor as long as they saw the added value of their advice. Three farmers did perceive mastitis as one of the main problems on their farm (Table 2).

Wait-and-See-ers. A prototypical wait-and-see-er can be illustrated by the following quote: "It would have been useful for us to have joined a study group on udder health, that's a fact. But it just didn't happen. And I could think of excuses such as 'I was too busy' or 'I didn't have time,' but you should make time for it. But I didn't." Of the 24 farmers interviewed, 5 were categorized as wait-and-see-ers. This group was in general open to advice from others, but rarely acted on their own initiative to search for information and to change the management on the farm. Farmers in this group stated that they were easy to approach by others and had a good relationship with their veterinarian. Three farmers did not share online milk inspection reports with their veterinarian or did not know whether 
they participated in that system. The 2 farmers who did exchange information never used it during visits from their veterinarian. Two farmers participated in study groups. The other farmers did not participate because they had not been asked to join or because it just came to nothing. They all read farm magazines. Some perceived the information received by mail as most important. They did not perceive the information they got as contradictory. All farmers in this group perceived mastitis as one of the main problems on their farm (Table 2).

Reclusive Traditionalists. A prototypical reclusive traditionalist can be illustrated by the following quote: "I don't like it when other people are looking into my farm business. I'm very much on my own." Of the 24 farmers interviewed, 6 were categorized as reclusive traditionalists. This group of farmers was very inward oriented. They did not like the interference of others on their farm. They had few contacts with other farmers and did not feel the need to compare their farm with others'. The interviewed farmers did not seek alliance with other farmers. They stated that they tried to prevent visits from veterinarians and other advisors as much as possible because they thought that these people had a hidden agenda to make money. They did not like exchanging information with others because they felt uncomfortable when others had access to their farm data. They perceived the relationship with their veterinarian as poor, costs being the main reason for having as little contact as possible. The farmers in this group did not participate in regular herd health visits from their veterinarian. They were visited for the obligatory monitoring health visits, which they tried to keep as short as possible. Four farmers in this group, the only ones in this study, did not see the added value of a national mastitis control program. Their most important information source was farm magazines. They appreciated them and read them thoroughly. Four farmers in this category perceived mastitis as one of the main health problems on the farm (Table 2).

\section{DISCUSSION}

On the basis of the model derived from the qualitative, semistructured interviews, 4 groups of farmers can be distinguished among the ostensibly hard-to-reach farmers. Although most of them do consider mastitis to be a problem and perceive udder health as important, they vary in the ways they use information sources and deal with mastitis problems on their farms. In general, the udder health situation of the farmers in this survey does not seem to deviate from the Dutch national average, although their veterinarians often thought that the udder health status of these farms was unsatisfactory.

\section{The Hard-to-Reach Farmers Lack Motivation, Not Information}

The results of this study show that hard-to-reach farmers feel that they have enough knowledge to deal with mastitis and that they can easily have access to udder health information when they need it. This raises the question of why farmers who do perceive mastitis problems are not motivated to change their farm management. Such intention-behavior discrepancies have rarely been studied in the field of veterinary medicine and agri-industry (Dernburg et al., 2007). From the interviews, it can be concluded that most farmers either feel that the problem is not serious enough or are not convinced of the efficacy of the proposed prevention measures on their farms. This corresponds with findings on farmers' entrepreneurial behavior change in general (Gielen et al., 2003). Although farmers in this study have a strong demand for simple, shortterm, effective solutions, they know that mastitis is a multifactorial and complex disease and that a simple panacea does not exist. This reinforces farmers' beliefs that preventive measures are neither effective nor practical. This perception is one of the main reasons why recommended measures are not adopted (Chase et al., 2006; Garforth et al., 2006; Rehman et al., 2007). It also corresponds to the health belief model (Janz and Becker, 1984; Dernburg et al., 2007), which shows that changing a health behavior depends on one's belief in a health threat and in the effectiveness of available preventive measures. It can be hypothesized that farmers who perceive a lack of effective measures automatically also perceive the problem as less important because, to reduce cognitive dissonance, they accept that they cannot solve it (Festinger, 1957; Cameron, 2009). When the problem is perceived as less important, the information will not be considered relevant by the farmer and therefore will not reach the farmer (Griffin et al., 1999; Moore and Payne, 2007).

Furthermore, in studies exploring whether a certain udder health situation is perceived as a problem, it should be taken into account that farmers are part of a wider social context and are being influenced by many institutions, legislation, and common law (Leeuwis, 2004). Farmers' motivation to work - or not to workon udder health depends on many external factors, such as incentives for bulk milk SCC, milk price, and quota regulations (Valeeva et al., 2007), in addition to internal factors, such as their management style and attitudes (Barkema et al., 1999; Jansen et al., 2009).

\section{How to Define Hard-to-Reach Farmers?}

The analyses of the interviews showed that hard-toreach farmers are not a homogeneous group. The 4 dif- 
ferent types of farmers used many different information sources and they did not perceive a lack of information on udder health. The results of this study suggest that hard-to-reach farmers may not be as difficult to reach as is often assumed. Being hard to reach can be interpreted in several ways. First, hard to reach does not mean that they are not reached by any information at all. Apparently, these farmers receive a lot of information. Seen from the perspective of the sender of the message, hard to reach can mean either that there is no contact with the farmer at all or that farmers do not apply the available information on mastitis prevention measures. It seems that the definition of hard-to-reach farmers is more ambiguous than initially expected. As a consequence, it can be suggested that the hard-toreach farmers in this study have been selected on the basis of the definition of hard to reach as perceived by different veterinarians. Some veterinarians may have selected farmers for this study because they never have contact with them (e.g., the reclusive traditionalists) or because they have contact but the farmer is not willing to adopt the veterinarian's advice (e.g., the proactivists and do-it-yourselfers). Because this study is not a quantitative representation of all dairy farmers in the Netherlands, it is a moot point whether the 4 types discerned in our sample of hard-to-reach farmers are specific to hard-to-reach farmers or whether they exist among all farmers in the Netherlands, because many different types of farmers exist (Beaudeau et al., 1996; Barkema et al., 1999; Van der Ploeg, 1999).

The selection of farmers via the veterinarian may have led to a biased selection of hard-to- reach farmers because farmers who are hard to reach by the veterinarian are not necessarily hard to reach by other information sources (e.g., the proactivists, the do-it-yourselfers, and the wait-and-see-ers). When we define hard to reach as having hardly any access to the farmer in the first place, only the reclusive traditionalists seem to fall into this category, and they seem to be only a small proportion of all interviewed farmers. However, it should be taken into account that 13 farmers were approached but were not willing to participate. These farmers may also belong to the reclusive traditionalists, indicating that this group maybe larger than suggested by the results of this study.

\section{How to Reach the Hard to Reach?}

The results of this study show that there is much variation among farmers and the information sources they use. This needs to be taken into account in communication strategies used in future udder health improvement programs. It is advisable to aim directly at different types of farmers by segmentation and customization of the type and content of the message to the various farmers' perceptions, such as their goals, attitudes, and motivations (Bergevoet et al., 2004; Chase et al., 2006; Hawkins et al., 2008). This so-called tailored communication is proven to be effective in many behavior change interventions (Noar et al., 2007). Based on the results of this study, several suggestions can be made about ways to reach hard-to-reach farmers. When asked how they would like to spend money on a national mastitis program, the interviewed farmers in general stated that they preferred free visits from mastitis experts and having access to the latest research outcomes on, for example, the increase in cows' natural resistance to mastitis. However, to effectively disseminate these research results, the 4 types of hard-to-reach farmers need to be addressed differently.

The proactivists can be reached by making information easily accessible via the Internet or via newsletters. This group of farmers likes to read about the latest hot topics in research. One-to-one contact can also be beneficial provided that the advisor is considered by the farmer to be an expert in his or her field. Because this group uses a variety of information sources, of which the veterinarian is only one, information about disease prevention should be distributed via multiple channels, such as the animal feed industry or milk equipment suppliers.

Do-it-yourselfers also use a variety of information sources, but they are more critical about the information they receive and state that they receive contradictory information. For this group, extensive argumentation accompanied with clear cost-benefit information seems to be most appropriate. The most important thing is to communicate a consistent message. Because they rely on experience in practice, communication with this group can be effective during, for example, open farm days, demonstrations of products, distribution of free samples, and interaction with colleagues when visiting other farms. This group of farmers also reads farm magazines.

The wait-and-see-ers seem to be reluctant about change in general. Although they are open to new information and do perceive mastitis problems, they rarely take the initiative to act. Because these farmers are open to advice and see that there is much to gain in respect of udder health, intensive personal support may be a key initiative for this group. The veterinarian basically is the most suitable person for such intensive contact because these farmers' relationship with their veterinarian is good. Veterinarians, however, need to be proactive with respect to these farmers and they need to have sufficient communication skills to reach 
these farmers (Mee, 2007). Only then is it possible to develop farm-specific goals and a step-by-step action plan together with the farmer.

The reclusive traditionalists seem to be the most difficult group to communicate with. This group can be expected not to be easily motivated by others to work on udder health because they have little trust in personal contact with others. Therefore, farm magazines and mailings seem to be the best way to disseminate information to these farmers, including personalized, free, objective, and independent practical information, because they often read such information with interest. However, in general, such linear information sources are less effective in changing farmers' behavior than extension through interpersonal contact (Gielen et al., 2003). The reclusive traditionalists can be seen as the late majority or laggards in adoption processes (Rogers, 1995), and behavior changes in the short term should not be expected; this means that long-term communication strategies and repetition of messages are necessary to reach these farmers. Moreover, lifechanging events, such as building a new cowshed or the transfer of the farm management from father to son, can be an effective starting point for radical changes in farm management (Osler, 2006).

\section{CONCLUSIONS}

The results show that farmers who were presumed to be hard to reach by veterinarians were not a homogeneous group. They were not always badly informed about udder health and did not always experience udder health problems. They could be divided into 4 categories based on their trust in external information sources regarding mastitis and their orientation toward the outside world: proactivists, do-it-yourselfers, wait-and-see-ers, and reclusive traditionalists. When communication strategies of animal disease prevention programs are adjusted to the different types and needs of the farmers, ample opportunities exist to reach these farmers. There is especially much to gain in communication with do-it-yourselfers and wait-and-see-ers, but this demands a proactive role for veterinarians and extension specialists. Different types of farmers need to be approached in different ways and through different canals with information on udder health to effectively change their mastitis management.

\section{ACKNOWLEDGMENTS}

This study is part of the 5-yr mastitis program of the Dutch Udder Health Centre (Deventer, the Netherlands) and was financially supported by the Dutch Dairy Board (Zoetermeer, the Netherlands). The au- thors acknowledge the dairy farmers for their participation in this study.

\section{REFERENCES}

Andersen, H. J., and C. Enevoldsen. 2004. Towards a better understanding of the farmer's management practices-The power of combining qualitative and quantitative data. Pages 281-301 in Radgivning, Bev Aegelse Mellem Data og Dialog [Advisory Service Between Data and Dialogue]. PhD Thesis. H. J. Andersen, Danish Dairy Board, The Royal Veterinary and Agricultural University, Mejeriforeningen Danish Dairy Board, Arhus, Denmark.

Barkema, H. W., J. D. Van der Ploeg, Y. H. Schukken, T. J. G. M. Lam, G. Benedictus, and A. Brand. 1999. Management style and its association with bulk milk somatic cell count and incidence rate of clinical mastitis. J. Dairy Sci. 82:1655-1663.

Beaudeau, F., J. D. Van der Ploeg, B. Boileau, H. Seegers, and J. P. T. M. Noordhuizen. 1996. Relationships between culling criteria in dairy herds and farmers' management styles. Prev. Vet. Med. 25:327-342.

Bergevoet, R. H. M., C. J. M. Ondersteijn, H. W. Saatkamp, C. M. J. Van Woerkum, and R. B. M. Huirne. 2004. Entrepreneurial behaviour of Dutch dairy farmers under a milk quota system: Goals, objectives, attitudes. Agric. Syst. 80:1-21.

Bradley, A. 2002. Bovine mastitis: An evolving disease. Vet. J. 164:116-128.

Burton, R. J. F. 2004. Reconceptualising the 'behavioural approach' in agricultural studies: A socio-psychological perspective. J. Rural Stud. 20:359-371.

Cameron, K. A. 2009. A practitioner's guide to persuasion: An overview of 15 selected persuasion theories, models and frameworks. Patient Educ. Couns. 74:309-317.

Chase, L. E., O. L. Ely, and M. F. Hutjens. 2006. Major advances in extension education programs in dairy production. J. Dairy Sci. 89:1147-1154.

Dernburg, A. R., J. Fabre, S. Philippe, P. Sulpice, and D. Calavas. 2007. A study of the knowledge, attitudes, and behaviors of French dairy farmers toward the farm register. J. Dairy Sci. 90:17671774.

Festinger, L. 1957. A Theory of Cognitive Dissonance. Stanford University Press, Stanford, CA.

Garforth, C. J., K. Mc Kemey, T. Rehman, R. B. Tranter, R. J. Cooke, J. B. Park, P. T. Dorward, and C. M. Yates. 2006. Farmers' attitudes towards techniques for improving oestrus detection in dairy herds in South West England. Livest. Sci. 103:158-168.

Gielen, P. M., A. Hoeve, and L. F. M. Nieuwenhuis. 2003. Learning entrepreneurs: Learning and innovation in small companies. Eur. Educ. Res. J. 2:90-106.

Griffin, R. J., S. Dunwoody, and K. Neuwirth. 1999. Proposed model of the relationship of risk information seeking and processing to the development of preventive behaviors. Environ. Res. Sect. A 80:S230-S245.

Hawkins, R. P., M. Kreuter, K. Resnicow, M. Fishbein, and A. Dijkstra. 2008. Understanding tailoring in communicating about health. Health Educ. Res. 23:454-466.

Hektoen, L. 2004. Investigations of the motivation underlying Norwegian dairy farmers' use of homeopathy. Vet. Rec. 155:701707.

Jansen, J., R. J. Renes, and T. J. G. M. Lam. 2008. Mastitis control: Seize the opportunity. The role of veterinarians as effective udder health advisors. Pages 176-177 in Proceedings of the 47th Annual Meeting of the National Mastitis Council, New Orleans, LA. National Mastitis Council, Verona, WI.

Jansen, J., R. J. Renes, and T. J. G. M. Lam. 2010. Evaluation of two different communication strategies to improve udder health management. J. Dairy Sci. 93:604-612.

Jansen, J., B. H. P. Van den Borne, R. J. Renes, G. Van Schaik, T. J. G. M. Lam, and C. Leeuwis. 2009. Explaining mastitis incidence in Dutch dairy farming: The influence of farmers' attitudes and behaviour. Prev. Vet. Med. 92:210-223. 
Janz, N. K., and M. H. Becker. 1984. The health belief model: A decade later. Health Educ. Q. 11:1-47.

Kuiper, D., J. Jansen, R. J. Renes, C. Leeuwis, and H. G. Van der Zwaag. 2005. Social factors related to mastitis control practices: The role of dairy farmers' knowledge, attitude, values, behaviour and networks. Pages 576-582 in Mastitis in Dairy Production. Current Knowledge and Future Solutions. Proceedings of the 4th IDF International Mastitis Conference. Wageningen Academic Publishers, Maastricht, the Netherlands.

Lam, T. J. G. M., J. Jansen, B. Van den Borne, and J. Van Veersen. 2007. A structural approach of udder health improvement via private practitioners: Ups and downs. Pages 142-151 in Proceedings 46th Annual Meeting, National Mastitis Council, San Antonio, TX. National Mastitis Council, Verona, WI.

LeBlanc, S. J., K. D. Lissemore, D. F. Kelton, T. F. Duffield, and K. E. Leslie. 2006. Major advances in disease prevention in dairy cattle. J. Dairy Sci. 89:1267-1279.

Leeuwis, C. 2004. Communication for Rural Innovation. Rethinking Agricultural Extension. 3rd ed. Blackwell Science Ltd., Oxford, UK.

Mee, J. F. 2007. The role of the veterinarian in bovine fertility management on modern dairy farms. Theriogenology 68(Suppl. 1):S257-S265

Moore, D. A., and M. Payne. 2007. An evaluation of dairy producer emergency preparedness and farm security education. J. Dairy Sci. 90:2052-2057.

Noar, S. M., C. N. Benac, and M. S. Harris. 2007. Does tailoring matter? Meta-analytic review of tailored print health behavior change interventions. Psychol. Bull. 133:673-693.
Osler, M. 2006. The life course perspective: A challenge for public health research and prevention. Eur. J. Public Health 16:230.

Rehman, T., K. McKemey, C. M. Yates, R. J. Cooke, C. J. Garforth, R. B. Tranter, J. B. Park, and P. T. Dorward. 2007. Identifying and understanding factors influencing the uptake of new technologies on dairy farms in SW England using the theory of reasoned action. Agric. Syst. 94:281-293.

Rogers, E. M. 1995. Diffusion of Innovations. Free Press, New York, NY

Strauss, A., and J. Corbin. 1990. Basics of Qualitative Research. Grounded Theory, Procedures and Tactics. Sage Publications, London, UK.

Vaarst, M., B. Paarup-Laursen, H. Houe, C. Fossing, and H. J Andersen. 2002. Farmers' choice of medical treatment of mastitis in Danish dairy herds based on qualitative research interviews. J. Dairy Sci. 85:992-1001.

Vaarst, M., and J. T. Sørensen. 2009. Danish dairy farmers' perceptions and attitudes related to calf-management in situations of high versus no calf mortality. Prev. Vet. Med. 89:128-133.

Valeeva, N. I., T. J. G. M. Lam, and H. Hogeveen. 2007. Motivation of dairy farmers to improve mastitis management. J. Dairy Sci. 90:4466-4477.

Van der Ploeg, J. D. 1999. De Virtuele Boer [The Virtual Farmer]. Van Gorcum \& Cromp B.V., Assen, the Netherlands.

Wester, F. P. J., and V. Peters. 2004. Kwalitatieve Analyse. Uitgangspunten en Procedures [Qualitative Analysis. Keynotes and Procedures]. Coutinho B.V., Bussum, the Netherlands. 


\section{Interview topic}

Description of farm

and farmer

Main question asked

Subquestion that could be asked to further define the farmer's opinion

Could you describe your farm?

Size (e.g., number of cows, milk quota, land)

Housing and milking system

Off-farm activities

Age and education level of farmer

Age of the farm and number of employees

Future perspectives

Membership in farmers' organizations and unions

Participation in milk recording scheme

Participation in online system to share milk inspection reports with the veterinarian (PiR-DAP)

Risk perception To what extent is mastitis a problem for you?

What do you think of the statement "Mastitis is the bigge

Do colleagues have more or fewer mastitis problems?

Do you talk about mastitis with colleagues?

What is the most annoying aspect of mastitis?

What is the most annoying aspect of mastitis?
What grade would you give yourself with respect

What grade would you give yourself with respect to whether mastitis on your farm

is better or worse than in the past?

How many subclinical and clinical mastitis cases do you have on your farm per year?

What is your bulk milk SCC?

What is your satisfaction level for bulk milk SCC?

At what level of subclinical and clinical mastitis will you change your farm management?

How do you treat mastitis? What do you do when you suspect a mastitis case?

Prevention and Can you talk about

treatment of mastitis mastitis treatment

and prevention on your farm?

What are the most important causes of mastitis on the farm, and are they easy

Do you perceive treatment and prevention to be easy?

What do you do with cows with chronic high cell counts?

Do you change your management when you receive information about mastitis prevention?

What is the influence of external circumstances, such as milk price and milk quota regulations?

Need for information What do you think about the attention given

to treatment and prevention of mastitis in the media?

Use of mastitis

information sources information source?

Interaction with the veterinarian

Familiarity with and opinion about, the udder health project
How important is the veterinarian as an information source for you?

Do you know that there is a national udder health project?
Do you think you know enough about the treatment and prevention of mas should do more about mastitis? What are the reasons?

Why do you, or why do you not, use PiR-DAP and standard herd health visits from your vet?

Do you think that farmers have a need for more information about mastitis? From whom should it come?

Whom do you first contact when you have mastitis problems?

What is the role of information on the Internet, in farm magazines, or via standard mail?

Do you actively search for information, and what are you looking for?

Is more or less attention given to mastitis in the media?

What do you think of this information (e.g., is it clear, useful, implementable)?

Do you disagree with the information?

Some farmers seem to be hard to reach with mastitis information. Can you suggest why?

How do you interact with your veterinarian in practice?

Can you describe your relationship?

Can you describe the role of the veterinarian as consultant? Should he or she be more proactive?

Do you have the need for more information from your veterinarian on mastitis issues?

Should the veterinarian be more focused on treatment or more focused on prevention of mastitis?

Do you know about the Dutch Udder Health Centre?

What do you think of the project? Is the money well spent?

What do you do yourself to benefit from the udder health project?

Have you visited their webpage?

Did you participate in a study group on udder health?

Do you think that farmers' organizations and animal health organizations have an accurate

impression of mastitis problems and the way to solve them?

What if you were able to set up such a project? How would you do that? 